\title{
Behavioral trade-off on shell exchange and exploration of the white spotwrist hermit crab Pagurus criniticornis (Crustacea, Anomura, Paguridae)
}

\author{
Raquel C. Buranelli, Andrea T. P. Marcondes, Fábio A. Carbonaro, Mayara J. Miyazaki, \\ L. Miguel Pardo, Fernando L. Mantelatto*
}

\begin{abstract}
The regulatory mechanisms of shell selection and occupation by hermit crabs can be determined by many factors such as competition, risk of predation, shell size, type and availability and also by physical damage. However, the relative importance among them has been scarcely studied. The aim of this study was to investigate the influence of predator, shell quality and size in shell exchanges and exploratory behaviors of Pagurus criniticornis. The experiments were carried out by placing a hermit crab with a naturally damaged shell in an arena with or without a caged predator (the narrowback mud crab, Panopeus americanus) and 10 empty shells. Concerning the male data and the shell exchange dependency on the factors of shell quality and predator presence, we suggest that individuals were sensitive to the predator presence when carrying a damaged shell. This data could represent a clear trade-off between the benefit of occupying a better shell and the imminent risk of predation. Considering that shells provide protection and that extremely damaged shells may increase the risk of predation, the exchange behavior is directly related to the increase in protection from predators, even if the exchange activity itself exposes the animal to a high predation risk for a short time.
\end{abstract}

Key words: exploratory behavior, predation, shell benefit, shell exchange, shell protection

\section{Introduction}

The behavioral trade-off is very common in nature and strongly influences the adaptation process of individuals to environment and underlies patterns of individual performance and population success (Morrell, 2004; Skelly, 1995), especially if the outcome of the behavior affects any axes of fitness, such as survival or growth and reproductive performance.

Hermit crabs are excellent model species to test behavioral trade-off, given that they occupy and are highly dependent on gastropod shell resources. This occupation is related to protection against predation and reduction of osmotic and physical stress to which they are exposed, such as abrasion caused by variations in tide and wave actions (Reese, 1969; Garcia \& Mantelatto, 2001; Meireles et al., 2008).

The ability of occupying and carrying empty shells of gastropods is one of the reasons for the evolutionary success of these organisms (Conover, 1978). Nevertheless, the availability of empty and intact shells in the environment is generally low or limited and can strongly influence growth rates, size, reproduction and survival of hermit crabs, thus representing a limiting factor (Dominciano et al., 2009; Turra \& Denadai, 2004; Turra \& Leite, 2002).

Furthermore, the availability of shells is strongly affected by various factors such as the abundance of gastropods and their mortality 
rate in a particular habitat, beyond inter and intraspecific competition for shells (Reese, 1969). In situations in which there is a large availability of shells in the environment, the size of the hermit crabs may be correlated with the size of the shells inhabited (Abrams, 1980). In this sense, the fauna of gastropod (live and empty) shells is essential to hermit crab communities, especially those involving shell utilization and selection (Meireles et al., 2003).

Behind and correlated with the natural condition of the resource, the regulatory mechanisms of the pattern of shell selection and occupation by hermit crabs are determined by many factors such as competition, type of shell, shell size, shell internal volume, availability of empty shells and also by the physical damage that these shells may have (Garcia \& Mantelatto, 2001; Turra \& Denadai, 2004). Furthermore, shell selection could also be regulated by internal and external contexts (Billock \& Dunbar, 2011). In this circumstance, internal contexts could be represented by the animal motivations or needs, such as for a better shell, and the external ones are determined by environmental features, such as the presence of a predator (Billock \& Dunbar, 2011).

Considering that if hermit crabs are motivated to acquire better shells and that this could be considered as internal contexts, they need to make faster decisions and will be less distracted by any external contexts, such as signals of danger (Elwood, 1995; Billock \& Dunbar, 2011). In other words, when making decisions, hermit crabs take their own needs into account and this is what motivates exchange behavior (Billock \& Dunbar, 2011).

A behavioral trade-off is potentially produced if shell exchange or exploration imply a risk of predation (Fotheringham, 1976a; Hazlett, 1981) but also allow an exchange for a higher quality shell that could have great impact in growth or reproduction (Lancaster, 1988; Mantelatto \& Garcia, 1999; Raimondi \& Lively, 1986). Considering this, we aimed to investigate the trade-off between the risk of predation and the election of suitable shells during exploratory behavior and shell exchange in the tiny pagurid hermit crab, Pagurus criniticornis (Dana 1852). Considering that external contexts could be less distractive when the motivation of acquiring a better shell is really strong (Elwood, 1995), we intended to test the hypothesis that the hermit crabs exchange shells or display an exploratory behavior regardless of the presence of a predator. In addition, we tested the importance of shell quality (damaged or intact shell) and size of the hermit crabs in the outcome of the behavioral trade-off. To test the trade-off, we used naturally damaged or intact shells and a local predator of $P$. criniticornis.

\section{Material and Methods}

\section{Model species and field sampling}

Individuals belonging to the species Pagurus criniticornis and the crab used as predator (Panopeus americanus Saussure 1857) were sampled in the region of Araçá mangrove, in the city of São Sebastião $\left(23^{\circ} 40^{\prime} 4^{\prime \prime} \mathrm{S}-45^{\circ}\right.$ $23^{\prime} 9^{\prime \prime} \mathrm{W}$ ), along the northern coast of São Paulo State, Brazil.

Pagurus criniticornis is an adequate model for this kind of behavioral study due to some of its morphological and behavior features. This species is characterized by small size and the individuals are active in pools during low tides, making them easy to collect and utilize for laboratory observation. In addition, their geographical distribution is restricted to the western Atlantic, constituting an abundant population in the community of hermit crabs in the coast of São Paulo (Leite et al., 1998; Mantelatto \& Garcia, 2002; Melo, 1999; Turra \& Denadai, 2004).

Besides, $P$. criniticornis appears to be a better exploration competitor and acquires resources more rapidly than other species (Turra \& Denadai, 2004). Thus, although showing a 
preference for certain species of gastropod, $P$. criniticornis does not seem to present a more rigorous standard for selecting shells of higher quality or size, using the shells that are available in the area, even if eroded or damaged (Turra \& Denadai, 2004). This kind of strategy may enhance the predation risks by some predators, such as shell-breaking crabs (Turra \& Denadai, 2004).

Individuals were collected from the field on September 2013, during a single day, between 10 and 12 am by 6 people during one-hour effort. The individuals (carrying originally intact or damaged shells) were randomly hand-collected in tide pools, packed and transported to the laboratory where they were all kept together with flowing, oxygen-saturated seawater. An estimation of the percentage of damaged shells in nature was conducted by counting the number of individuals with damaged and intact shells of the total sampled. The field-collected shells were considered damaged when an evident perforation ( $>2 \mathrm{~mm}$ diameter) was found at the aperture level. Then, the individuals carrying approximately the same shell size were chosen and separated for the experiments. Among the individuals selected, hermit crabs were divided according to the conditions of the shells (intact or damaged).

\section{Laboratory experiments}

All experiments were carried out in the marine lab, six hours after sample collection. Aiming to analyze if shell condition and predator presence influence the shell exploration and shell exchange by $P$. criniticornis, intact empty shells were offered to hermit crabs in the presence or absence of predators.

Considering the preference of $P$. criniticornis to use gastropod shells belonging to the common snail Cerithium atratum (Born 1778) and Morula nodulosa (Adams 1845) (Faria, 2004), we only used shells of $C$. atratum, which is in greater abundance at our study site and is predominantly occupied by $P$. criniticornis
(Dominciano et al., 2009). Therefore, all shells offered to hermit crabs during experiments and all shells (damaged or intact) naturally used by the collected hermit crabs belonged to $C$. atratum.

A full factorial design was elaborated to test shell choice under combinations of shell quality and predator presence/absence. Thus the following treatments were used: Treatment 1: (a) damaged shell and predator presence $(n=26)$, (b) intact shell and predator presence $(n=10)$; Treatment 2: (a) damaged shell and predator absence $(n=26),(b)$ intact shell and predator absence $(n=26)$. The inconsistency in sample size was due to low availability of intact shells.

For each replicate, one hermit crab carrying their original (damaged or intact) shell was placed in an experimental arena (diameter: $43 \mathrm{~cm}$; depth: $20 \mathrm{~cm}$ ) with or without the presence of a predator crab, and ten empty, intact and numbered shells were offered (Fig. 1). Empty shells were approximately the same size as the one occupied by the treatment individual, when obtained from the field.

In the case of the predator treatments, the crab was placed in a central position inside a transparent, plastic cage to prevent contact between animals, but allowing water flowing and odor detection. The selection of the predator was based on previous studies, in which brachyuran crabs, such as Cancer productus Randall 1840, were identified as potential predators of hermit crabs (Vance, 1972). Considering the region of this study and the brachyuran fauna available, the narrowback mud crab, Panopeus americanus, was chosen since it is commonly found in this environment (Vergamini \& Mantelatto, 2008). One of us (FLM) has previously observed the predatory activity of $P$. americanus on $P$. criniticornis at the study site.

Experiments were conducted under conditions similar to the tide pools where the animals were collected: controlled temperature $\left(16^{\circ}-17^{\circ} \mathrm{C}\right)$, salinity $(33-34)$, and natural day- 


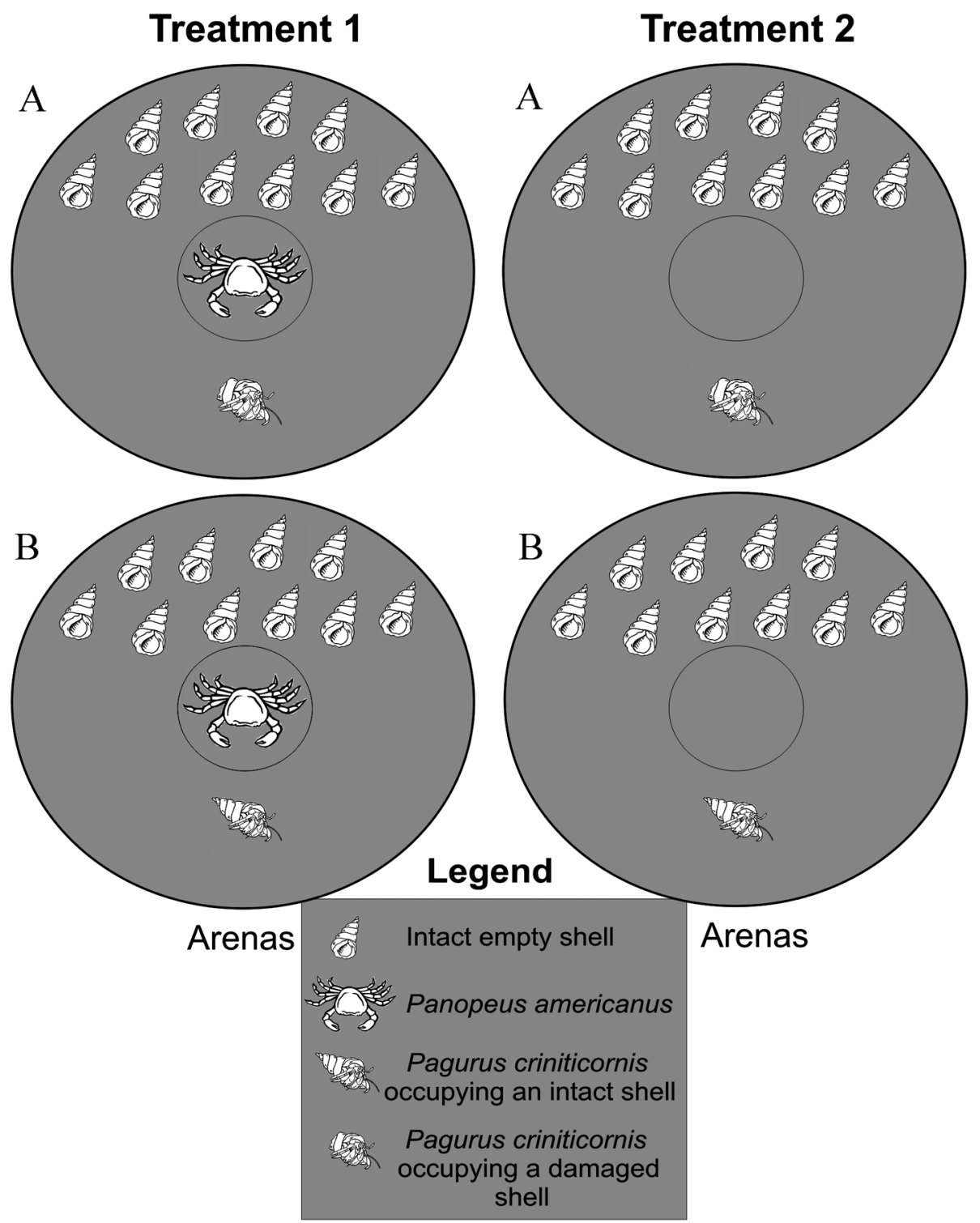

Fig. 1. Schematic model of the treatments used in the experiment. Treatment 1: a) damaged shell and predator presence, $b$ ) intact shell and predator presence; Treatment 2: a) damaged shell and predator presence, b) intact shell and predator absence.

light (L12:D12). Each animal was used only once, to avoid any acquired behavior.

Each replicate was observed every 15 minutes for two hours. The behavior exhibited by the individuals and occurrences of shell exchange and/or exploration were recorded.

For each observation, two elements of behavior were categorized: (1) Shell exchange: considered when the hermit crab entered a shell and remained in it for at least 30 minutes; (2) Exploratory behavior: the act of (a) entering and immediately leaving shells or (b) examining an empty shell but not occupying it. These two types of behavior were considered "exploratory", since both of them did not necessarily result in the hermit crab using the shell examined for 30 minutes. Shell exchange and exploration imply both in the exposure of the 
soft abdominal part of the body. Nevertheless, shell exchange is normally a rapid movement while exploratory behavior may constitute repetitive exposures, being interpreted as more risky in the presence of predators.

At the end of each replication, the hermit crabs either carrying or not carrying new shells were removed from the arenas, and individuals were removed from their shells by heating the apex of these structures (Garcia \& Mantelatto, 2001). Hermit crabs were sexed according to the position of the gonopores and their shield length (SL) measured from the tip of the rostrum to the V-shaped groove at the posterior edge with a caliper $(0.1 \mathrm{~mm})$. All shells occupied by hermit crabs (original and exchanged) were measured for aperture width and wetweight $(0.0001 \mathrm{~g})$.

To test if the hermit crabs exchanged shells or displayed an exploratory behavior regardless of predator presence (null hypothesis), a log likelihood ratio (G-test) test of independence with William's correction was performed separately for males and females, using the software R for Windows, v. 3.0.1. We categorized hermit crab size (for both male and female groups) as Large (SL $\geq 3.00 \mathrm{~mm}$ ) and Small $(\mathrm{SL} \leq 2.99 \mathrm{~mm})$ individuals. These conditions and shell type (intact or damaged) were included in the analysis (G test). Finally, a T-test was conducted, using the software BioEstat for Windows v. 5.3, to assess whether there was a significant difference between the wet weight and the aperture widths of the original and exchanged shells, including all cases of all treatments for males.

Voucher specimens were deposited in the Crustacean Collection of the Biology Department (CCDB) of the Faculty of Philosophy, Sciences and Letters at Ribeirão Preto (FFCLRP) at the University of São Paulo, Brazil (catalogue number CCDB 4721).

\section{Results}

In total, 397 individuals of Pagurus criniticornis were collected, but we selected only 72 individuals for the experiments, being 55 males, 6 non-ovigerous females and 11 ovigerous females. Among all collected individuals, $67 \%$ of them had their shells already damaged. The size of the animals (SL) ranged from 1.98 to $5.97 \mathrm{~mm}(3.02 \pm 0.67 \mathrm{~mm})$ for males and from 2.06 to $3.80 \mathrm{~mm} \mathrm{(2.94 \pm}$ $0.52 \mathrm{~mm}$ ) for females.

Among the total individuals tested, 38\% of males and $18 \%$ of females performed shell exchange, and $55 \%$ of males and $47 \%$ of females performed shell exploratory behavior. The analysis of shell exchange for males indicated that this behavior was dependent on shell quality, on interaction of predator presence and shell quality, and on interaction between shell quality and size (Table 1). Nevertheless, for females this behavior was independent of all of these factors (Table 2).

Table 1. Pagurus criniticornis. G-test for all variables analyzed for shell exchange for males; sample size $=55 ;^{*}=$ significant dependence.

\begin{tabular}{lrrl}
\hline \multicolumn{1}{c}{ Variable } & G & df & p-value \\
\hline Predator & 0.5144 & 1 & 0.4732 \\
Shell quality & 8.7588 & 1 & $0.003081^{*}$ \\
Size & 0.2587 & 1 & 0.611 \\
Predator and shell quality & 11.0729 & 3 & $0.01134^{*}$ \\
Predator and size & 0.7584 & 3 & 0.8594 \\
Shell quality and size & 8.9978 & 3 & $0.002932^{*}$
\end{tabular}

Table 2. Pagurus criniticornis. G-test for all variables analyzed for shell exchange for females; sample size $=17$; No significant dependence was detected for all variables.

\begin{tabular}{lccc}
\hline \multicolumn{1}{c}{ Variable } & $\mathrm{G}$ & $\mathrm{df}$ & $\mathrm{p}$-value \\
\hline Predator & 0.2393 & 1 & 0.6247 \\
Shell quality & 0.0052 & 1 & 0.9427 \\
Size & 0.4836 & 1 & 0.4868 \\
Predator and shell quality & 1.2243 & 3 & 0.7472 \\
Predator and size & 1.9371 & 3 & 0.5856 \\
Shell quality and size & 1.2243 & 3 & 0.7472 \\
\hline
\end{tabular}


Table 3. Pagurus criniticornis. G-test for all variables analyzed for shell exploration for males; sample size $=55$; No significant dependence was detected for all variables.

\begin{tabular}{lccc}
\hline \multicolumn{1}{c}{ Variable } & G & df & p-value \\
\hline Predator & 2.1377 & 1 & 0.1437 \\
Shell quality & 2.5937 & 1 & 0.1073 \\
Size & 0.0095 & 1 & 0.9225 \\
Predator and shell quality & 4.7114 & 3 & 0.1942 \\
Predator and size & 2.2044 & 3 & 0.5311 \\
Shell quality and size & 5.3343 & 3 & 0.1489 \\
\hline
\end{tabular}

Table 4. Pagurus criniticornis. G-test for all variables analyzed for shell exploration for females; sample size $=17$; No significant dependence was detected for all variables.

\begin{tabular}{llll}
\hline \multicolumn{1}{c}{ Variable } & \multicolumn{1}{c}{$\mathrm{G}$} & $\mathrm{df}$ & $\mathrm{p}$-value \\
\hline Predator & 1.346 & 1 & 0.246 \\
Shell quality & 0.6472 & 1 & 0.4211 \\
Hermit crab size & 0.5122 & 1 & 0.4742 \\
Predator and shell quality & 2.775 & 3 & 0.4276 \\
Predator and size & 2.9929 & 3 & 0.3927 \\
Shell quality and hermit crab size & 1.291 & 3 & 0.7313 \\
\hline
\end{tabular}

The wet weight of the exchanged shells for males in all situations (predator presence or absent, and original shells damaged or not) ranged from 0.8762 to $1.8082 \mathrm{~g}$, averaging $1.1628 \pm 0.5842 \mathrm{~g}$, versus 0.6911 to $2.2519 \mathrm{~g}$, averaging $1.3463 \pm 0.3283 \mathrm{~g}$ of the original shells. The aperture width of the exchanged shells ranged from 5.17 to $12.37 \mathrm{~mm}$, averaging $8.7742 \pm 4.3717 \mathrm{~mm}$, versus 3.04 to $13.41 \mathrm{~mm}$, averaging $9.34 \pm 2.14 \mathrm{~mm}$ of the original shells. There was no significant difference between the wet weight of the original and exchanged shells $(\mathrm{t}=1.4626 ; \mathrm{df}=21 ; \mathrm{p}$ $($ unilateral $)=0.0804 ; p($ bilateral $)=0.1607)$ or between the aperture widths of exchanged versus original shells $(\mathrm{t}=0.4251$; $\mathrm{df}=21$; $\mathrm{p}$ (unilateral $)=0.3379 ; \mathrm{p}($ bilateral $)=0.6758)$. For females, data was not used since only 3 females exchanged their shells.

Considering the data of shell exploration, the results indicated that the shell exploratory behavior was not dependent on shell quality, predator presence, size or any of these factors together for both sexes (Tables 3 and 4).

\section{$\square$ Discussion}

In general, our results indicate that, for Pagurus criniticornis, there is a range of factors, besides predator presence, that influences shell exchange, and that some of them could represent trade-offs between immediate and long-term survival.

The result that $67 \%$ of the sampled animals already had damaged shells might indicate that empty, good shells have low availability in the environment analyzed. Considering that empty shells are rare in habitats with abundant populations of hermit crabs (Bertness, 1980; Hazlett, 1970), as in the study area, the limitations of this resource in a natural environment may be reduced by seeking out and using the resources that are available, as well as through exchanges among individuals. In other words, this would indicate that this species uses mostly damaged shells due to the scarcity of good, empty shells, maximizing resource exploitation. Besides, this corroborates the fact that $P$. criniticornis does not maintain a rigorous standard of selection for shells of higher quality or suitable size, using the shells that are available in the area, even if eroded or damaged (Turra \& Denadai, 2004).

Evidence in agreement with this idea is that individuals of $P$. criniticornis are found to inhabit eroded or damaged shells in higher frequency than other coexistent species, such as Clibanarius antillensis (Turra \& Denadai, 2004). The dominance hierarchy between these two species could explain this condition, so that individuals of $C$. antillensis are able to outcompete with $P$. criniticornis for higher quality shells in agonistic encounters (Turra \& Denadai, 2004). This fact, along with the significant dependence of shell exchange on shell quality could be related to Lancaster's (1988) concept whereby hermit crabs are efficient on exploring available resources but also contest- 
ing the ones that are not, being particularly good at solving the problems of limited resources.

From the results obtained, we reject the null hypothesis for males, because most variables tested influenced shell exchange, particularly when they interacted (i.e. shell quality with predator presence and shell quality with crab size). Nevertheless, we fail to reject the null hypothesis for females and for the exploratory behavior data for both sexes. Since the sample group for female data was low and heterogeneous, with the clustering of ovigerous and non-ovigerous females, it could have generated an impact on results by poor statistical power. Accordingly, we only used male data for the following discussion and comparison.

Concerning male P. criniticornis, our data suggest that shell exchanges are dependent on the factors including shell quality and predator presence. We can assume that individuals were sensitive to predator presence when carrying a damaged shell. This situation could represent a clear trade-off between the benefit of occupying a better shell and the imminent risk of predation.

The choice of a shell for occupancy may be influenced by previous experience in a variety of ways (Hazlett, 1992) and so the presence of an unused resource, could encourage exploitation and exchange behavior. Thus, when resources are scarce and shell exchange becomes beneficial, hermit crabs tend to show an exchange behavior (Carlon \& Ebersole, 1995). The benefit of the exchange and the subsequent contestation of a better resource seem clear, since the shell exchange behavior showed dependency on shell quality for males.

On the other hand, the exchange behavior can expose the individual, even if for a short period to potential predation, and thus this behavior may be inhibited by the presence of a predator. Nevertheless, despite the presence of a predator, the individuals performed exchanged behavior, even if they represented a lower percentage in comparison with the animals that were exposed to the predator, indicating behavioral plasticity of these animals (Garcia \& Mantelatto, 2001). Furthermore, this behavior could be in agreement with the fact that if the motivation of acquiring a better shell is really strong, the hermit crabs could be less distracted by any external contexts, such as, in this case, the presence of a predator (Elwood, 1995; Billock \& Dunbar, 2011). More recently, experimental studies have detected that $P$. criniticornis demonstrated a great tendency to abandon it shells under conditions of simulated disturbance (Turra \& Gorman, 2014).

Considering that shells provide protection against predators (Bertness, 1981a, 1981b) and shells of an inappropriate size or which are extremely damaged may increase the risk of predation (Vance, 1972), it is plausible to think that exchange behavior is directly related to a potential increase of protection from predators. Vance (1972), when analyzing the predation of Pagurus granosimanus (Stimpson 1859), found that the individuals became significantly more vulnerable to predation when unable to retreat completely into their shells. Thus, considering the exposure to which an individual is subjected when using a small or extremely damaged shell, and that the chances of avoiding predation are directly related to the protection offered by the shell (Angel, 2000), the behavior of exchange would be beneficial, even if this behavior exposes the animal to predation for a short time.

Our results indicate a strong trade-off between the effort of finding and occupying a better shell, and the risk of predation to which the hermit crab is exposed during shell exchanges. This trade-off could represent a conflict of choice between immediate survival, represented by the maintaining of the same shell, and long-term survival, represented by the exchange for a better shell that would be beneficial in many aspects, such as future reproductive gains, reducing vulnerability, and 
save energy for growth, as well as many other factors that operate to determine resource selection, as discussed below.

With regard to the size classes and shell quality, our results for the G-test indicated that the shell exchange behavior is dependent on these factors interaction. This is probably related to the fact that hermit crabs are in constant activity searching for adequate shells (Bertness, 1981b), requiring new and larger shells as they grow (Fotheringham, 1976a, 1976b; Markham, 1968; Spight, 1977). Considering that the use of suitable shells shows high influence on growth (Turra \& Leite, 2002; Turra \& Denadai, 2004; Dominciano et al., 2009) and carrying a shell of inappropriate size can inhibit growth, it is likely that a quantifiable exchange behavior contributes to changes in growth rates (Angel, 2000). Thus, smaller individuals with faster growth rates show more intensive behaviors of exchange and exploration. Furthermore the smaller shells possibly carried by smaller individuals are more easily damaged or destroyed by predators (Borjesson \& Szelistowki, 1989), which could intensify this kind of behavior.

From our observation on shell exploration by hermit crabs, we found no relationships between shell exploration and all the variables considered. With regard to shell quality, the exploration in search of a better shell is based on many factors, such as an individual's vulnerability when carrying an extremely damaged shell, as discussed above. With respect to the presence of a predator, in this case an intensive exploration for shells could expose the individual to a greater exposure to predators compared to a simple exchange (FLM pers. obs.). Nevertheless, the non-dependency of shell quality or predator presence on shell exchange behavior could simply indicate that hermit crabs using damaged shells tend to change rather than explore shells.

Results for females also showed no relationships of any variables with shells exchange, probably by the low number and the heteroge- neity of the sample group for females rather than non behavioral responses. Nevertheless, sex based differences in shell preferences patterns have been detected in other tiny hermit crabs (Pardo et al., 2007), therefore females could respond to other variables, such as type of shells, especially the ovigerous females. Since there were no equivalent sample sizes to males, females and ovigerous females, could have badly generated an impact on the results. A rearrangement of the data could indicate differences in shell exchange and exploitation because there are differences in shell utilization among sex explained by intraspecific competition, which is closely related to individual size, energy expenditure, reproductive activity and growth (Abrams, 1988; Mantelatto \& Dominciano, 2002). Furthermore, in other studies males show adaptive advantages with respect to the size of shells used, considering resource competition among individuals (Mantelatto \& Garcia, 2000).

In situations in which there was shell exchange for males, the difference between the original and exchanged shells considering wet weight and aperture width was not statistically significant. These results differ from other found in the literature for other species (Bertness, 1980; Hahn, 1998; Mantelatto \& Dominciano, 2002).

For other species, such as Pagurus sp., some studies indicate that individuals prefer heavy, thick-apertured shells that resist predation by generalized crushers (Bertness, 1980). In addition, some species of hermit crabs adjust their preferences for shells according to water flow, by selecting heavier shells when living in higher flow environments (Hahn, 1998), or adjust the benefits of carrying heavy shells that give better protection from predators instead the direct benefits of the rapid growth obtained using lighter, less protective shells (Alcaraz et al., 2015). Thus, the occupation of a heavier shell helps to avoid dislocation, protects the individual from predators, wave impact, and abrasion, 
but also demands higher energy costs (Hahn, 1998; Mantelatto \& Dominciano, 2002). In cases of hypoxic conditions, as observed in the intertidal region of study, the hermit crabs prefer smaller, lighter shells in comparison with the chosen shells under normal conditions even though this selection may expose the individual to predation (Côté et al., 1998).

In conclusion, considering the importance of shells for hermit crabs as a primary source of protection from predators, physical stress, and the influence of shells on growth and reproduction (Abrams, 1988; Bertness, 1981c; Dominciano et al., 2009; Mantelatto \& Garcia, 2000; Meireles et al., 2008; Turra \& Denadai, 2004; Turra \& Leite, 2002; Vance, 1972), different features of shells have different impacts on the fitness of the individual (Bertness, 1981b). Shell choice should be based on survival and protection provided (Garcia \& Mantelatto, 2001), but a shell feature that maximizes one of the components of fitness may not necessarily coincide with those that maximize others (Bertness, 1981b). In other words, this means that hermits crabs face different trade-offs related to the behavior of choice, selection, and exchange of shells, indicating that different factors may affect behavior, depending on environmental features, sex, individual size, shell size, and shell quality. Particularly for $P$. criniticornis, our results indicate an evident trade-off between the benefit of occupying a better shell and the risk of predation during shell exchange behavior.

\section{Acknowledgments}

The authors express their deep gratitude to the Postgraduate Program in Comparative Biology, Department of Biology, Faculty of Philosophy, Science and Letters at Ribeirão Preto (FFCLRP), University of São Paulo (USP) and to FAPESP (Temático Biota 2010/50188-8) for a grant supporting travel to the northern coast of São Paulo and for facili- ties during the development of the course on Experimental Marine Biology. We also thank all participants in the course and their help during field activities and to the anonymous reviewers for their suggestions and contributions towards improving this article. RCB and MJM were under continued support for $\mathrm{PhD}$ and technician fellowships from FAPESP (Proc. 2012/06299-5 and 2014/08507-0, respectively). FLM thanks CNPq for research fellowships (Proc. 302748/2010-5; 304968/2014-5) and CAPES (Ciências do Mar II Proc. 2005/201423038.004308/2014-14) for additional support. The collections of specimens conducted in this study complied with current applicable state and federal laws of Brazil (DIFAP/ IBAMA/126/05; permanent license to FLM. for collection of Zoological Material No. 11777-1 MMA/IBAMA/SISBIO).

\section{Literature Cited}

Abrams, P. A., 1980. Resource partitioning and interspecific competition in a tropical hermit crab community. Oecologia, 46: 365-79.

Abrams, P. A., 1988. Sexual differences in resource use in hermit crabs; consequences and causes. In: G. Chelazzi, \& M. Vannini (eds.), Behavioral Adaptations to Intertidal Life. Plenum Press, New York, pp. 283-296.

Alcaraz, G., C. E. Chávez-Solís, \& Kruesi, K., 2015. Mismatch between body growth and shell preference in hermit crabs is explained by protection from predators. Hydrobiologia, 743: 151-156.

Angel, J. E., 2000. Effects of shell fit on the biology of the hermit crab Pagurus longicarpus (Say). Journal of Experimental Marine Biology and Ecology, 243: 169-184.

Bertness, M. D., 1980. Shell preference and utilization patterns in littoral hermit crabs of the Bay of Panama. Journal of Experimental Marine Biology and Ecology, 48: 1-16.

Bertness, M. D., 1981a. Conflicting advantages in resource utilization of a tropical rocky inter- 
tidal hermit crab community. Ecology, 62: 411-425.

Bertness, M. D., 1981b. Conflicting advantages in resource utilization: the hermit crab housing dilemma. The American Naturalist, 118(3): 432-437.

Bertness, M. D., 1981c. Seasonality in tropical hermit crab reproduction in the Bay of Panama. Biotropica, 13(4): 292-300.

Billock, W. L., \& Dunbar, S. G., 2011. Shell and food acquisition behaviors: evidence for Contextual Decision Hierarchies in hermit crabs. Journal of Experimental Marine Biology and Ecology, 398: 26-32.

Borjesson, D. L., \& Szelistowski, W. A., 1989. Shell selection, utilization and predation in the hermit crab Clibanarius panamensis Stimpson in a tropical mangrove estuary. Journal of Experimental Marine Biology and Ecology, 133(3): 213-228.

Carlon, D. B., \& Ebersole, J. P., 1995. Life-history variation among three temperate hermit crabs: the importance of size in reproductive strategies. Biological Bulletin, 188: 329337.

Conover, M. R., 1978. The importance of various shell characteristics to the shell-selection behavior of hermit crabs. Journal of Experimental Marine Biology and Ecology, 32: 131-142.

Côté, I. M., Reverdy, B., \& Cooke, P. K., 1998. Less choosy or different preference? Impact of hypoxia on hermit crab shell assessment and selection. Animal Behaviour, 56: 867873.

Dominciano, L. C. C., Sant'Anna, B. S., \& Turra, A., 2009. Are the preference and selection patterns of hermit crabs for gastropod shells species- or site-specific? Journal of Experimental Marine Biology and Ecology, 378: 15-21.

Elwood, R. W., 1995. Motivational change during resource assessment by hermit crabs. Journal of Experimental Marine Biology and Ecology, 193: 41-55.

Faria, F. C. R., 2004. Biologia populacional e pa- drão de ocupação e seleção de conchas pelo ermitão Pagurus criniticornis (Crustacea, Anomura, Paguridae) da Ilha Anchieta, Ubatuba (SP). 56 pp. Master's thesis, Universidade de São Paulo (USP)—FFCLRP.

Fotheringham, N., 1976a. Population consequences of shell utilization by hermit crabs. Ecology, 57: 570-578.

Fotheringham, N., 1976b. Hermit crab shells as a limiting resource (Decapoda: Paguridae). Crustaceana, 31: 193-199.

Garcia, R. B., \& Mantelatto, F. L., 2001. Shell selection by the tropical hermit crab Calcinus tibicen (Herbst, 1971) (Anomura, Diogenidae) from Southern Brazil. Journal of Experimental Marine Biology and Ecology, 265: 1-14.

Hahn, D. R., 1998. Hermit crab shell use patterns: response to previous shell experience and to water flow. Journal of Experimental Marine Biology and Ecology, 228: 35-51.

Hazlett, B. A., 1970. The effect of shell size and weight on the agonistic behavior of a hermit crab. Zeitschrift für Tierpsychologie, 27: 369-374.

Hazlett, B. A., 1981. The behavioral ecology of hermit crabs. Annual Review of Ecology and Systematics, 12: 1-22.

Hazlett, B. A., 1992. The effect of past experience on the size of shells selected by hermit crabs. Animal Behaviour, 44: 203-205.

Lancaster, I., 1988. Pagurus bernhardus (L.)—an introduction to the natural history of hermit crabs. Field Studies, 7: 189-238.

Leite, F. P. P., Turra, A., \& Gandolfi, S. M., 1998. Hermit crabs (Crustacea: Decapoda: Anomura), gastropod shells and environmental structure: their relationship in southeastern Brazil. Journal of Natural History, 32: 15991608.

Mantelatto, F. L., \& Dominciano, L. C. C., 2002. Pattern of shell utilization by the hermit crab Paguristes tortugae (Diogenidae) from Anchieta Island, Southern Brazil. Scientia Marina, 66(3): 265-272. 
Mantelatto, F. L., \& Garcia, R. B., 1999. Reproductive potential of the hermit crab Calcinus tibicen (Anomura) from Ubatuba, São Paulo, Brazil. Journal of Crustacean Biology, 19(2): 268-275.

Mantelatto, F. L., \& Garcia, R. B., 2000. Shell utilization pattern of the hermit crab Calcinus tibicen (Diogenidae) from Southern Brazil. Journal of Crustacean Biology, 20(3): 460-467.

Mantelatto, F. L., \& Garcia, R. B., 2002. Hermit crab fauna from the infralitoral area of Anchieta Island (Ubatuba, Brazil). In: E. E. Briones, \& F. Alvarez (eds.), Modern Approaches to the Studies of Crustacean. Kluwer Academic/Plenum, New York, pp. 137-145.

Markham, J., 1968. Notes on the growth patterns and shell utilization of the hermit crab Pagurus bernhardus (L.). Ophelia, 5: 189205.

Meireles, A. L., Biagi, R., \& Mantelatto, F. L., 2003. Gastropod shell availability as a potential resource for the hermit crab infralittoral fauna of Anchieta Island (SP), Brazil. Nauplius, 11(2): 99-105.

Meireles, A. L., Biagi, R., \& Mantelatto, F. L., 2008. Influence of prior experience on shell selection by the white spotwrist hermit crab Pagurus criniticornis (Crustacea: Paguridae). Hydrobiologia, 605(1): 259 263.

Melo, G. A. S., 1999. Manual de identificação dos Crustacea Decapoda do litoral brasileiro: Anomura, Thalassinidae, Palinuridae, Astacidae. Plêiade, São Paulo, São Paulo.

Morrell, L. J., 2004. Are behavioural trade-offs all they seem? Counter-intuitive resolution of the conflict between two behaviours. Behavioral Ecology and Sociobiology, 56(6): 539-545.

Pardo, L. M., Piraud, F., Mantelatto, F. L., \& Ojeda, F. P., 2007. Ontogenetic pattern of resource use by the tiny hermit crab Pagurus villosus (Paguridae) from the temperate Chilean coast. Journal of Experimental
Marine Biology and Ecology, 353: 68-79.

Raimondi, P. T., \& Lively, C. M., 1986. Positive abundance and negative distribution effects of a gastropod on an intertidal hermit crab. Oecologia, 69: 213-216.

Reese, E. S., 1969. Behavioral adaptations of intertidal hermit crabs. American Zoologist, 9(2): 343-355.

Skelly, D. K., 1995. A behavioral trade-off and its consequences for the distribution of Pseudacris treefrog larvae. Ecology, 76: 150-164.

Spight, T. M., 1977. Availability and use of shells by intertidal hermit crabs. Biological Bulletin, 152(1): 120-133.

Turra, A., \& Denadai, M. R., 2004. Interference and exploitation components in interespecific competition between sympatric intertidal hermit crabs. Journal of Experimental Marine Biology and Ecology, 310: 183-193.

Turra, A., \& Leite, F. P. P., 2002. Shell utilization patterns of a tropical intertidal hermit crab assemblage. Journal of the Marine Biological Association of United Kingdom, 82(1): 97-107.

Turra, A., \& Gorman, D., 2014. Subjective resource value and shell abandoning behavior in hermit crabs. Journal of Experimental Marine Biology and Ecology, 452: 137-142.

Vance, R. R., 1972. The role of shell adequacy in behavioral interactions involving hermit crabs. Ecology, 53(6): 1075-1083.

Vergamini, F. G., \& Mantelatto, F. L., 2008. Microdistribution of juveniles and adults of the mud crab Panopeus americanus (Brachyura, Panopeidae) in a remnant mangrove area in the southwest Atlantic. Journal of Natural History, 42(23/24): 1581-1589.

\section{Addresses}

(RCB, MJM, FLM) Laboratory of Bioecology and Crustacean Systematics (LBSC), Department of Biology, Faculty of Philosophy, Science and Letters at Ribeirão Preto (FFCLRP), University of São Paulo (USP), Av. Bandeirantes 3900, Ribeirão Preto, São Paulo, 
Brazil; (RCB, ATPM, FAC) Postgraduate Program in Comparative Biology, FFCLRP/ USP; (LMP) Instituto de Ciencias Marinas y Limnologicas, Laboratorio Costero Calfuco, Universidad Austral de Chile, Casilla 567, Valdivia, Chile.
E-mail addresses

(RCB) raquel.buranelli@gmail.com (ATPM) athayspm@gmail.com (FAC) fabiocarbonaro@usp.br (MJM) mayarajm@hotmail.com (LMP) luispardo@uach.cl (FLM)*flmantel@usp.br

*Corresponding author 